GEOgraphia

Niterói, Universidade Federal Fluminense

ISSN 15177793 (eletrônico)

Vol.19, N40, 2017: mai./ago.

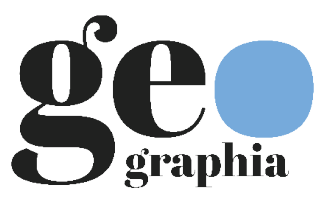

\title{
SUBIMPERIALISMO, NA VISÃO DE UM GEÓGRAFO*
}

\section{Milton Santos}

Underdevelopment and Poverty: A Geographer's View, pp. 38-47. In: The Latin American in Residence Lectures, Number III in the series, 1972-1973. University of Toronto,1975.

"Subimperialismo", a tese do Dr. Ruy Mauro Marini é tanto uma teoria da ciência política quanto uma explicação de política econômica, tão bem como um novo esforço de reinterpretação histórica e prospectiva. Longe de surgir para ser um novo slogan, esse tema parece, ao contrário, ser capaz de servir como ponto de partida de uma ideologia política e um comportamento político, assim como um instrumento efetivo de análise das realidades presentes e das perspectivas do futuro imediato.

Por outro lado, esse tema será capaz, mais uma vez, de substanciar a unidade das ciências humanas e sua ativa solidariedade na explicação de importantes fenômenos da nossa época, assim como no esforço de encontrar a solução para esses fenômenos. É este o motivo pelo qual um geógrafo não irá sentir-se tão distante de um tópico como este, o qual é apenas em aparência remoto às preocupações dos especialistas do espaço.

\section{"Subimperialismo" de acordo com Ruy M. Marini}

Se eu entendi corretamente o procedimento intelectual de Ruy Marini, penso que seu esforço poderia ser resumido em três partes: a descrição do contexto histórico, a tipologia das situações presentes e, finalmente, a formulação de perspectivas, incluindo tanto o diagnóstico quanto a solução para a situação.

Depois de ter lido alguns dos trabalhos do Dr. Marini (dentre eles "Brazilian Sub-imperialism", Monthly Review, vol. 23, n 9, pp. 14-24; e Sous-Développement et Révolution em Amérique Latine, Paris: Edition Maspero, 1972, especialmente os capítulos 2 e 4), me pareceu que a definição de subimperialismo pode ser encontrada na conjunção dos seguintes fatores: 1) a concentração de produção e renda, cuja consequência é "a superexploração do trabalho, que é o grande pilar do esquema subimperialista"; 2) a ainda mais frequente necessidade de recorrer ao setor externo; 3 ) a situação de crise criada por essa política econômica e a necessidade de apelar para novas formas de consumo estatal, tais como a instalação de infraestrutura e a indústria militar, o que serve como meios de buscar uma nova expansão do mercado para bens de capital. 
Esses dados autorizam Ruy Marini a definir subimperialismo como uma "fusão dos interesses militares e do grande capital" (...), "a forma que o capitalismo dependente assume ao alcançar o estágio do capital monopolista e financeiro", uma situação na qual "o problema do mercado constitui o eixo do esquema (subimperialista)". O Estado, portanto, ocupa um lugar fundamental na explicação do subimperialismo. Este Estado tem o papel de regulador dos "choques" (o termo é empregado por M. Mamalakis, "The Theory of Sectorial Clashes", Latin American Research Review, vol. IV, n 3 , Fall 1969, pp. 9-46) entre os interesses de diversos setores, assim como o de proteger as crescentes necessidades do sistema econômico internacional contra a demanda mais ou menos expressa pelo empobrecimento das massas e, também, das classes médias, cujo destino depende da conjuntura alcançada pelos setores dominantes da economia.

Desde o tempo do governo do Presidente João Goulart, explica Ruy Marini, "as tentativas de redistribuição da renda provaram-se uma pobre solução do ponto de vista do grande capital". Depois do Golpe de Abril de 1964 a situação reverteu-se ao seu curso "normal" por meio da "crescente concentração de renda e de suas fontes produtivas". Àquele tempo, o novo regime apresentou novas soluções. Dentre elas, a mais significante foi "elevar a exportação de bens manufaturados" e "aumentar a demanda interna por bens de capital". "A expansão das exportações exigiu o crescimento do nível tecnológico, o que, por sua vez, implicou grandes possibilidades para a absorção de bens de capital". Conjuntamente, e como consequência, havia um "crescimento dos gastos do Estado por meio de uma ativa política de desenvolvimento da infraestrutura de transporte e eletrificação..." indispensável para a expansão da produção de bens de capital e para a exportação de bens manufaturados.

Como em evidência, tudo estava inter-relacionado... Mas tal política teve um preço. "A grande indústria foi desnacionalizada" e ali ocorreu um "reforço da tendência do capitalismo brasileiro ao monopólio no sentido de criar uma estrutura produtiva capaz de competir no mercado internacional". Contudo, o imperialismo internacional recusou dividir alguns campos de produção, tal como a indústria aeronáutica e a tecnologia nuclear, e impediu o seu desenvolvimento local. Esse movimento concentrado e a política de crédito imposta pelo governo, com a concordância do Fundo Monetário Internacional, levaram à bancarrota inúmeras médias e pequenas empresas, enquanto os salários reais, o salário mínimo real e o salário médio, todos, decresceram. A política de exportação de bens manufaturados, escandalosamente ajudada por subsídios estatais, resultou em um crescimento do Produto Interno Bruto (PIB) a taxas japonesas e a um estilo brasileiro de empobrecimento da maior parte da população.
Finalmente, a necessidade de uma política de exportação agressiva deixou as forças armadas brasileiras superequipadas, levando o Brasil, afırma Marini, a buscar uma posição de hegemonia no subcontinente, o que serve aos interesses das grandes firmas, sem levar em conta também as aspirações populares ou a soberania das nações vizinhas.

Apesar de concordar com a maioria desses fundamentos e conclusões, a crítica básica que eu faria ao trabalho de Marini é relativa à sua negligência em tratar o problema em termos de sistema-mundo, o que é essencial para compreender o subdesenvolvimento em diversos níveis. A carência de tal abordagem impede uma visão mais geral da questão, a qual deve ser tão atual quanto histórica, permitindo a análise e a perspectiva apropriadas.

O caso brasileiro é apenas um submodelo de um fenômeno mais geral.

\section{"Subimperialismo" e "países industrializados subdesenvolvidos"}

Eu gostaria agora de examinar o ponto de vista histórico dos países subdesenvolvidos e questionar se não há um sinônimo entre aquilo que Ruy Marini chamou de "subimperialismo" e o que eu tenho intitulado de "países subdesenvolvidos industrializados" (Milton Santos, Les Villes du Tiers Monde, Paris: Editions N. Th. Genin, Librairies Techniques, 1971). A velha taxonomia políticogeográfica que põe de um lado os países industrializados e de outro os países subdesenvolvidos (modestamente chamadosdepaísesnão-industrializados)jánãotemmais significado, pois agora existem países subdesenvolvidos industrializados, tais como Brasil, Argentina, México, Índia, Egito e, talvez, África do Sul.

Uma industrialização dependente e pontual caracteriza tais países subdesenvolvidos industrializados. Dependente porque a espinha dorsal do presente sistema histórico, que é a tecnologia, é um privilégio dos países do centro: a dependência tecnológica provoca, por sua vez, a dependência financeira e uma dependência das políticas econômicas dos países periféricos, assim como uma dependência nas formas de organização da produção, a exemplo dos monopólios. A dependência também é evidente nos padrões de localização industrial. Por conta de tudo isso, a industrialização dependente é também pontual, pois grandes firmas tendem a se concentrar em certos pontos do espaço nacional onde já existe uma concentração de infraestrutura e de capital de giro.

Um certo número de outras características diferencia fundamentalmente os países subdesenvolvidos industrializados dos países desenvolvidos. Primeiramente, os 
países subdesenvolvidos industrializados têm sindicatos ineficientes e uma verdadeira ausência de organização sindical. Isto decorre de diversas razões, dentre elas, da degradação do mercado de trabalho. A dificuldade dos sindicatos manifestarem suas existências é agravada quando a ditadura é estabelecida no país, a qual passa a arbitrar conflitos de interesses em favor de empresas multinacionais e dos monopólios. Segundo: a opinião pública, controlada e transmitida por poderosos meios de publicidade, comandados tanto de dentro do país quanto de alhures, é ela mesma privada de meios para analisar corretamente as decisões da política econômica formulada pelo Estado. Finalmente, a dependência em si e as contradições inerentes à necessidade de sucessivas adaptações conjunturais força os monopólios, que são o principal fator da instabilidade política, a se protegerem de tal instabilidade e, assim, tornarem-se ainda mais poderosos e relativamente mais potentes do que nos países desenvolvidos. Eles alcançam esse objetivo por meio de apoio diplomático que lhes tem sido abertamente garantido por cerca de duas décadas.

Essas opções de política econômica encerram o país em um ciclo vicioso. A cada dia, a necessidade de importar para ser capaz de exportar aumenta, assim como a necessidade de exportar para que seja possível importar. Isto significa um duplo empobrecimento porque a política de exportação leva, por um lado, à necessidade inevitável de se utilizar tecnologia a nível internacional e, por outro lado, a uma busca de uma competitividade inalcançável. Ao passo que a escala das firmas se amplia, os recursos nacionais disponíveis para outros usos decrescem: a dificuldade para a indústria ser verdadeiramente competitiva ao nível internacional compele o Estado a garantir vantagens à exportação que são crescentemente exorbitantes. Os subsídios para certos produtos chegam a alcançar $50 \%$, como acontece no Brasil; e ao fim, as classes pobres pagam a conta, e duplamente: primeiro, por meio do sistema tributário que é principalmente composto de impostos indiretos, afetando principalmente as classes mais pobres, e, em segundo lugar, por conta de que o conluio entre a necessidade de importar e de exportar impede, na lógica do monopólio, a realização da expansão desejável da produção orientada ao consumo de massa. Esse conluio contribui ao fato que o salário real continua a diminuir e também reduz as oportunidades para uma política econômica nacional independente.

Assim, se há uma interdependência entre os países desenvolvidos, os países subdesenvolvidos industrializados são dependentes. Na realidade, quanto maior a modernização, maior é a dependência. Como sujeito e objeto de uma troca crescentemente desigual, eles são seduzidos a desenvolverem uma produção orientada externamente, a qual entrava a industrialização nacional. Essa situação pré-crise cria entre eles um apetite imperialista sobre os países menos desenvolvidosque são susceptíveis a se tornarem clientes. Esta forma periférica de imperialismo, chamada de "subimperialismo" por Marini, aparece quando o país subdesenvolvido se torna industrializado, especificamente quando pode prover um mercado interno com bens de consumo, embora o mercado possa ser pauperizado pelos monopólios, e quando possui indústrias de bens de capital, cuja capacidade rapidamente torna-se superior à capacidade de absorção do já comprimido mercado nacional.

A situação do subimperialismo ou imperialismo dependente não é exclusividade brasileira, mas é uma situação geral em todos os países subdesenvolvidos industrializados. As possibilidades externas da ação subimperialista, a qual cria um "segundo grau de dependência", são contingentes à situação geopolítica, à evolução histórica e às condições presentes dos demais países, especialmente os vizinhos. Isso seria útil para comparar as situações do Brasil, da Argentina, da República da África do Sul e da Índia com aquelas do México e do Egito. Até que ponto é isto uma consequência exclusiva do nível de desenvolvimento nacional ou das opções de política econômica e política internacional adotadas por cada país?

\section{Organização da produção e organização espacial}

Os países subdesenvolvidos industrializados são caracterizados por um mecanismo interno, exclusivamente seu, que tem repercussões na organização geral da produção, no emprego e na organização do espaço. Estudos sistemáticos e amplos relativos às relações entre formas de organização da produção e modelos de organização espacial são consideravelmente deficientes nos países subdesenvolvidos. Mesmo geógrafos e outros especialistas poderiam desempenhar um papel apreciável na compreensão dos fenômenos da pobreza e sua manifestação espacial, desde que haja uma interrelação entre todos esses fenômenos.

Tal abordagem serviria igualmente para demonstrar o caráter secundário e residual de certas teorias correntes que, se examinadas separadamente, são apenas uma abordagem parcial, no que dizem respeito a questões tais como marginalidade, dualismo, fenômeno migratório, macrocefalia, ou a questão de cidades primárias e o falso problema do tamanho ótimo das cidades, sem esquecer o inexaurível problema da "habitação" padronizada como um problema fundamental dos países subdesenvolvidos, mas que aparece mais vinculado ao mercado. Essas abordagens, além de não serem completas, apenas reúnem, desde um ponto de vista analítico, epifenômenos, 
e de um ponto de vista corretivo apenas oferecem soluções provisórias.

A questão essencial que deve ser encarada pelos geógrafos, economistas espaciais ou espaciologistas que trabalhem em países subdesenvolvidos refere-se às relações entre formas de organização da produção e aquelas de organização espacial na escala nacional ou macro-espacial, e nas escalas meso ou micro-espacial. Tal análise também inclui uma consequência ao nível da vida individual, pois cada cidadão possui um "valor" diferente como produtor ou consumidor em relação à posição por ele ocupada no espaço nacional. Assim, a conclusão possível seria a de que não existe solução para os problemas urbanos por meio da cidade e que o chamado planejamento urbano e regional é apenas um embuste se examinado separado da política econômica e social de todo o país.

\section{Fases do período tecnológico e a conexão entre a organização do espaço e o subimperialismo}

Paramelhorcompreenderasrelaçõescontemporâneas entre a organização da produção e a organização espacial, é absolutamente necessário considerar o fato de que o sistema temporal presente corresponde ao período tecnológico e é dividido em duas fases ou dois segmentos históricos do ponto de vista do comportamento dos polos do sistema. Esta divisão é evidente quando se considera a história do subdesenvolvimento como sendo amalgamada à história da divisão internacional do trabalho. Desse modo, durante a primeira fase do período tecnológico ocorreu aquilo que os economistas sulamericanos têm com justiça intitulado de "a importação da divisão internacional do trabalho". Isto é, ocorreu a transferência, sob certas condições e impondo certas garantias, do maquinário de produção industrial dos países desenvolvidos para os países subdesenvolvidos por meio da utilização in loco do "proletariado externo", assim chamado por Toynbee, mas retendo um "terciário externo" nos países dominantes (externo em respeito aos países dominantes). Consequentemente, os níveis mais altos do terciário são deficientes nos países em industrialização. Uma pesquisa recente desenvolvida pela Harvard Business School descobriu que 600.000 empregos nos EUA eram dependentes de operações estrangeiras de corporações multinacionais baseadas nos Estados Unidos.

Durante a primeira parte do período tecnológico, as indústrias criadas segundo o processo de substituição de importação constituíram, em certos pontos privilegiados do país e que são atualmente as poucas metrópoles completas dos países subdesenvolvidos, uma máquina de produção capaz de efeitos de multiplicação locais (reservo essa expressão "metrópole completa" à mais importante aglomeração, desde um ponto de vista industrial, nos países subdesenvolvidos industrializados. Ver Milton Santos, Les Villes du Tiers Monde, op. cit., chap. IX).

A situação é diferente na segunda fase. A "mania de crescimento" (a expressão é de Esra J. Mishan, The Costs of Economic Growth, New York: Praeger, 1967, pp. 3-8) tendo atingido seu paroxismo, justapôs um mercado interno comprimido a uma necessidade crescente de exportação. A deterioração dos termos de troca piora e a contradição entre a necessidade simultânea de importar e exportar enfraquece o valor internacional das moedas dos países subdesenvolvidos. A importação da divisão internacional do trabalho da primeira fase continua, enquanto outros elementos entram em foco com o desenvolvimento da exportação de bens manufaturados. Na maior parte do tempo, subsídios do Estado permitem essas exportações, resultando em países pobres que ajudam os países ricos. Paradoxalmente, uma camisa feita no Brasil pode ser comprada a melhor preço em Boston do que em São Paulo.

Por outro lado, a preparação para a exportação de matéria-primageraverdadeiros "enclaves". Aexistênciade dois tipos de enclaves pode ser verificada. Primeiramente, há enclaves reconhecidos caracterizados por cidades industriais, como Ciudad Guyana, na Venezuela, que são simplesmente partes do planejamento econômico de países ricos, embora planejadores econômicos mercenários os representem como elementos do planejamento econômico e espacial de países pobres. Há também enclaves ocultos, quando indústrias de exportação se estabelecem em grandes cidades para usufruir de infraestrutura e mão de obra barata.

A primeira fase do período tecnológico implica, do ponto de vista da organização espacial, uma acumulação em certas aglomerações que já monopolizam, por exemplo, os meios de transporte ou comércio de produtos agrícolas. É por isto que se pode falar de uma acumulação cumulativa, que favorece a instalação de estruturas monopolistas mais ou menos abertas, com a desacumulação de capital e novamente acumulação cumulativa da pobreza, ambas nas cidades e no campo. Os países subdesenvolvidos industrializados, em geral, experienciaram uma industrialização "precoce", especificamente antes da primeira guerra mundial (o caso do Egito é uma exceção e um exemplo essencial de efetividade da vontade política). É o monopólio, e não a explosão demográfica, falta de capital ou mercado, que ocasiona a terciarização da maioria das cidades, a macrocefalia dos polos econômicos (geralmente a capital dos países) e a migração interna, ou mesmo externa, o subemprego e o desemprego. Nessa primeira 
fase, o espaço obteve uma especialização horizontal com um tipo de estrutura urbana piramidal do ponto de vista da produção industrial. Essa especificidade confere um incontestável papel de direção à metrópole econômica do país, apesar da sua dependência vis à vis os países estrangeiros. Cidades grandes, médias e pequenas são todas dependentes das cidades maiores e certos efeitos da multiplicação recíproca podem aparecer, ao tempo que isto é possível, a despeito das estruturas monopolistas, para preservar uma parte da decisão em matéria de organização do espaço e da produção, sendo esta principalmente destinada ao mercado interno.

Durante a segunda fase do período tecnológico a exportação torna-se uma preocupação essencial tanto para o Estado quanto para as firmas nacionais e, especialmente, para as internacionais. Assim, o crescimento econômico das cidades pode ser realizado totalmente separado do restante da região ou país. Decisões relativas à atividade de produção dependem cada vez mais da conjuntura interna às grandes firmas, mas externa aos países, sendo o espaço objeto de uma multiplicidade de influências oriundas dos polos de decisão em várias escalas ${ }^{1}$.

Na primeira fase, os monopólios, estabelecidos onde os equipamentos privilegiados já estavam localizados, que estão nas grandes cidades, foram compelidos a levar em conta as firmas pré-existentes. Assim, isto permitiu uma rede de interdependência que facilitou o crescimento e constituiu uma fundação para a difusão espacial dos resultados conquistados.

Durante a segunda fase, as firmas multinacionais ou extra-regionais, de acordo com a natureza de suas operações, não exigem, na realidade, economias externas, senão elas mesmas as criam. As externalidades são de especial importância, mas a este respeito é o Estado que é o provedor, seja diretamente ou por meio de aparentes empréstimos generosos de organizações bancárias internacionais. Esses gastos de equipamento são externalidades, que indicam que a população de um país dominado é mais uma vez forçada a financiar as grandes firmas de países dominantes.

Essa alocação de recursos tem repercussão no nível da organização espacial. O espaço é organizado de acordo com o jogo dialético dos fatores de concentração e dispersão. As estruturas monopolistas constituem

\footnotetext{
${ }^{1} \mathrm{~A}$ importação de novas tecnologias geralmente indica a necessidade de importar novas matérias-primas. Por exemplo, no Estado da Bahia, os agricultores mais pobres do Nordeste árido, longe de serem removidos do litoral, poderiam obter dinheiro por meio da venda de algodão. A fabricação moderna que utiliza fibras sintéticas vai afetar o mercado agrícola e empobrecer os agricultores e as cidades vizinhas, e este empobrecimento não é exclusivo das pequenas cidades.A nova equação de emprego, um resultado do aumento de escala das firmas, força todas as cidades do país, sejam ou não aglomerações industriais, a se tornarem cidades terciárias. Este é o caso em São Paulo, onde o número de favelas, assim como o índice de desemprego, tem recentemente aumentado ao nível mais alto de todos os tempos.
}

um fator de concentração, a difusão de informação e consumo desempenha um papel de dispersão, ao passo que o Estado tem papel misto. Quando o Estado funciona em apoio aos monopólios, por meio da concentração de infraestruturas, ele age como um elemento da concentração econômica e demográfica. Quando ele dissemina equipamentos territoriais de natureza social, tal como hospitais e escolas, ou mesmo oferece incentivo a camponeses, ele é um fator de dispersão. A cada tempo, quando há uma tendência de equipar um país de acordo com uma certa ideologia de crescimento como um fator de desenvolvimento, os recursos tornam-se menos e menos disponíveis aos fatores de dispersão.

Isto explica porque, em uma situação de subimperialismo, há um perfeito sinônimo entre, por um lado, monopólios e firmas multinacionais, e por outro, macrocefalia e suas consequências: desemprego, subemprego, marginalidade, terciarização e o assim chamado "dualismo".

Há aí uma certeira solidariedade entre os crescimentos urbano, demográfico e espacial, e o externamente orientado crescimento econômico urbano monopolista. Mas os planejadores econômicos oficiais do imperialismo continuam a pregar o crescimento estatístico à la Rostov ao mesmo tempo que fingem combater a macrocefalia, a expansão urbana e, mais recentemente, a poluição. Eles propõem fórmulas, tais como descentralização concentrada, cujo efeito inicial é reduzir ainda mais os recursos nacionais que de outra forma serviriam para elevar as condições de vida da população ou ajudar o estabelecimento de uma política de produção que melhor serviria ao interesse geral. Consequentemente, a teoria da descentralização concentrada numa situação de imperialismo dependente, ou mesmo de capitalismo dependente, pode apenas ajudar a agravar uma concentração concentrada e fazer o empobrecimento mais generalizado. Esta é a situação ideal para a implantação mais fácil dos monopólios e para o reforço da situação de subimperialismo. 